\title{
Optimization of Amino Acid Sequence of Fmoc- Dipeptides for Interaction with Lipid Membranes
}

Pablo G. Argudo, ${ }^{1}$ Rafael Contreras-Montoya, ${ }^{2}$ Luis Álvarez de Cienfuegos, ${ }^{2 * *}$ María T. MartínRomero, ${ }^{1}$ Luis Camacho, ${ }^{1}$ Juan J. Giner-Casares ${ }^{1, *}$

${ }^{1}$ Departamento de Química Física y T. Aplicada, Instituto Universitario de Investigación en Química Fina y Nanoquímica IUIQFN, Facultad de Ciencias, Universidad de Córdoba (UCO), Campus de Rabanales, Ed. Marie Curie, E-14071 Córdoba, Spain

${ }^{2}$ Departamento de Química Orgánica, Facultad de Ciencias, Universidad de Granada, (UGR), C. U. Fuentenueva, Granada E-18071, Spain. 


\section{ABSTRACT}

Fmoc-dipeptides appear as a highly relevant building block in smart hydrogels and nanovehicles for biological applications. The interactions of the Fmoc-dipeptides with the cell membrane determine the efficiency of the nanomaterials based on the Fmoc-dipeptides, as the internalization of nanovehicles for drug delivery. Here we aim at the understanding of the interplay of the interactions between the Fmoc-dipeptides and a phospholipid surface as a function of the aminoacid sequence. The DMPA (1,2-dimyristoyl-sn-glycero-3-phosphate) phospholipid in Langmuir monolayers was used as a model cell surface. A set of seven derivatives of Fmocdipeptides with a broad range of hydrophobicity were included. Mixed monolayers composed by DMPA:Fmoc-dipeptide in equimolar ratio were built and characterized in situ at the air/water interface. Surface pressure-molecular area isotherms $(\pi-A)$, Brewster Angle Microscopy (BAM) and UV-vis reflection spectroscopy $(\Delta R)$ were combined to provide a holistic picture on the interactions of the Fmoc-dipeptide with the phospholipid molecules. An increase in the hydrophobicity led to an enhanced interaction of the Fmoc-dipeptide and DMPA molecules. The compression of the mixed monolayer could displace a significant fraction of the Fmoc-dipeptide from the monolayer. A high hydrophobicity promoted self-assembly of the Fmoc-dipeptides over interaction with the phospholipid surface. The interplay of these two phenomena was analyzed as a function of the aminoacid sequence of the Fmoc-dipeptides. The toxicity effect of Fmoc-FF could be observed and detailed at the molecular level. This study suggests that the adjustment of the hydrophobicity of the Fmoc-dipeptides within a defined range might optimize their efficiency for the interaction with the lipid membranes. A semiquantitative guide for the chemical design of Fmoc-dipeptides for biological applications is proposed herein. 


\section{INTRODUCTION}

Dipeptides can self-assemble as single building blocks and in combination with biologically active molecules, e.g., photosensitizers for nanomedicine. ${ }^{1}$ The dipeptide structure is highly interesting as a self-assembling moiety when included in bioconjugates for drug delivery. ${ }^{2-4}$ Bioinspired materials including dipeptides have been shown to assemble into intriguing nanostructures. ${ }^{5-8}$ The Fmoc (9-fluorenylmethyloxycarbonyl) group confers relevant self-assembly and amphiphilic properties to the dipeptides. ${ }^{9-12}$ Fmoc-dipeptides display antibacterial activity and can be used to prevent biofilm formation. ${ }^{13}$ Self-assembled nanostructures of Fmoc-dipeptides and related building blocks have been proposed for cancer therapy. ${ }^{14}$ The aminoacid residues might play a role as well in the assembly process, as shown for complementary peptide nucleic acids. ${ }^{15-17}$

Dipeptides can efficiently affect cell membranes, as demonstrated by the diphenylalanine dipeptide in combination with liposomes to render cytoskeleton-like structures. Such phenomenon is highly relevant when considering dipeptides for drug delivery, taking into account the fusion mechanism between the delivery vehicle and the cell membrane as shown by Li et al. ${ }^{18}$ Permeation of dipeptides through the phospholipid membrane has been studied by computer simulations, pointing at the hydrophobicity/hydrophilicity balance and interfacial activity as the key parameters for permeation. ${ }^{19,20}$ Given the relevance and interest of Fmoc-dipeptides for biological applications, the ability to tune the interaction and impact of such dipeptides over the cell membrane is key in the rational chemical design of the Fmoc-dipeptides. Indeed, a programmed increase of the hydrophobicity in $\mathrm{pH}$-responsive nanogels for drug delivery allowed Yang et al. an enhanced tumor accumulation through an efficient internalization into bulk tumor cells. ${ }^{21}$ The 
significant role of hydrophobic interactions in the self-assembly of dipeptide derivatives for biomedical application on biosurfaces has been highlighted by Adams and Zelzer. ${ }^{22}$

The surface activity of the Fmoc-dipeptides determines the gel-forming properties, with the partition coefficient as key parameter. ${ }^{23}$ We have recently related the partition coefficient with the capability of the Fmoc-dipeptides to self-assemble onto microstructures at the air/liquid interface. ${ }^{24}$ The Langmuir technique appears as a highly suitable platform for studying the interaction of Fmoc-dipeptides with phospholipid monolayers as model membranes: the available area per phospholipid molecule can be finely tuned and the events at the phospholipid interface can be conveniently studied. ${ }^{25-29}$ Pyrene-pentapeptide derivatives have been studied using the Langmuir technique, leading to intriguing mesostructures with prospect applications as bioactive coatings. ${ }^{30}$ Hydrophobic dipeptides can form Langmuir monolayers under suitable experimental conditions, including acidic $\mathrm{pH}$ of the aqueous subphase. ${ }^{31}$ The interactions of a set of Fmocdipeptide derivatives with Langmuir monolayers of the 1,2-dimyristoyl-sn-glycero-3-phosphate (DMPA) phospholipid as model lipid for the cell membrane have been studied herein. In situ Brewster Angle Microscopy and UV-vis reflection spectroscopy have offered detailed insights into the interaction between the Fmoc-dipeptides and the phospholipid monolayer as a function of the aminoacid sequence at the air/water interface. A similar procedure for applying surface pressure, i. e., compression at a constant rate, have been applied for all DMPA:Fmoc-dipeptide monolayers. Drastically different effects on the DMPA monolayer have been obtained as a function of the Fmoc-dipeptide derivative. The relevance of the extent and type of interactions between the DMPA and each Fmoc-dipeptide derivative has been assessed. This study aims to design of a set of general rules for the molecular design of Fmoc-dipeptide derivatives for biological applications. 


\section{MATERIALS AND METHODS}

Materials. Fmoc-LG, Fmoc-AA, Fmoc-GG and Fmoc-FF were purchased from Bachem Co. Fmoc-MF, Fmoc-RF and Fmoc-CF were synthesized as described elsewhere. ${ }^{24}$ DMPA was purchased from Avanti Lipids and used as received. Solvents were used without further purification and purchased from Aldrich (Germany). Hydrochloric acid 37\% was PRS-Codex purchased from Panreac and used as received. The initial $1 \mathrm{mM}$ solutions of Fmoc-RF, Fmoc-CF, Fmoc-MF and Fmoc-FF dipeptides were prepared in dichloromethane. The initial $1 \mathrm{mM}$ solutions of Fmoc-GG, Fmoc-AA and Fmoc-LG were in methanol. A mixture of chloroform:methanol (3:1 in volume), was used for dissolving DMPA at a concentration of $1 \mathrm{mM}$. The Fmoc-dipeptides and the DMPA were co-spread in molar ratio DMPA:Fmoc-dipeptide 1:1. Ultrapure water produced by a Millipore Milli-Q unit, and pre-treated by a Millipore reverse osmosis system $(>18.2 \mathrm{M} \Omega \mathrm{cm})$ was used to prepare the acid solution for subphase. The subphase temperature was $21{ }^{\circ} \mathrm{C}$ with $\mathrm{pH}$ 2. All experiments were performed on tables with vibration isolation (antivibration system MOD2 S, Accurion, Göttingen, Germany) in a large class 100 clean room.

Surface pressure-area $(\boldsymbol{\pi}-\boldsymbol{A})$ isotherms. Two different models of Nima troughs (Nima Technology, Coventry, England) were used, both provided with a Wilhelmy type dynamometric system using a strip of filter paper: a NIMA 611D with one moving barrier for the measurement of the reflection spectra, and a NIMA 601, equipped with two symmetrical barriers to record BAM images. The monolayers were compressed at a speed of $0.03 \mathrm{~nm}^{2} \mathrm{~min}^{-1}$ molecule ${ }^{-1}$. Assuming a complete loss of the spread Fmoc-dipeptide molecules from the air/liquid interface to the bulk subphase, a maximum concentration of $10^{-7} \mathrm{M}$ would be achieved. A bulk concentration of ca. $10^{-}$ ${ }^{3} \mathrm{M}$ was required to record a significant change in the surface tension of water according to the Polavarapu et al. ${ }^{32}$. We therefore assume the surface tension for the subphase is not modified by 
the effect of mass transfer of a given fraction of the Fmoc-dipeptide molecules from the mixed monolayers to the bulk subphase. The compression speed allowed a detailed study of the DMPA:Fmoc-dipeptide mixed monolayers and assured that the recorded isotherms were not affected by kinetic effects.

UV-vis reflection spectroscopy. UV-visible reflection spectra at normal incidence as the difference in reflectivity $(\Delta R)$ of the film-covered water surface and the bare surface were obtained with a Nanofilm Surface Analysis Spectrometer (Ref SPEC ${ }^{2}$, supplied by Accurion GmbH, Göttingen, Germany).

Brewster angle microscopy (BAM). Images of the film morphology were obtained by Brewster angle microscopy (BAM) with a I-Elli2000 (Accurion GmbH) using a Nd:YAG diode laser with wavelength $532 \mathrm{~nm}$ and $50 \mathrm{~mW}$, which can be recorded with a lateral resolution of $2 \mu \mathrm{m}$. The image processing procedure included a geometrical correction of the image, as well as a filtering operation to reduce interference fringes and noise.

\section{RESULTS AND DISCUSSION}

A set of seven Fmoc-dipeptides was included in this study, see Figure 1 for the general molecular structure and Table 1 for the detailed aminoacid sequence for each derivative of Fmoc-dipeptide. The Fmoc-dipeptide molecules tend to solubilize in bulk water at neutral $\mathrm{pH}$, forming micelles and other aggregates. ${ }^{33}$ Therefore, a diluted solution of $\mathrm{HCl}$ with $\mathrm{pH}=2$ was used as a subphase according to the study on hydrophobic dipeptides by Clegg and Adams. ${ }^{31}$ The carboxylic acid of the Fmoc-dipeptides was protonated. ${ }^{34}$ The outer cell membrane was modelled as a Langmuir monolayer of the phospholipid Dimyristoylphosphatidic acid (DMPA), showing no net charge at acid $\mathrm{pH}^{35,36}$ Note that the commonly used Phosphatidylcholine (PC) phospholipids will be 
positively charged at such $\mathrm{pH}$ conditions and therefore would not be a suitable phospholipid molecule for mimicking the eukaryotic membrane..$^{37,38}$

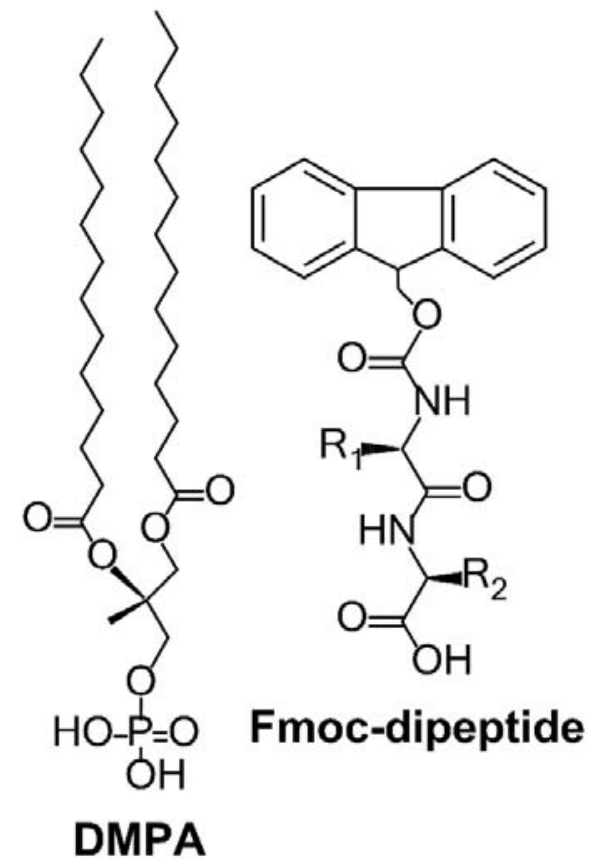

Figure 1. Molecular structures for the DMPA phospholipid and the Fmoc-dipeptide derivatives.

Table 1. Abbreviation and chemical groups for each derivative of Fmoc-dipeptide.

\begin{tabular}{|c|c|c|}
\hline Abbreviation & $\mathbf{R}_{\mathbf{1}}$ & $\mathbf{R}_{\mathbf{2}}$ \\
\hline Fmoc-GG & $-\mathrm{H}$ & $-\mathrm{H}$ \\
\hline Fmoc-AA & $-\mathrm{CH}_{3}$ & $-\mathrm{CH}_{3}$ \\
\hline Fmoc-LG & $-\mathrm{CH}_{2}-\mathrm{CH}-\left(\mathrm{CH}_{3}\right)_{2}$ & $-\mathrm{H}$ \\
\hline Fmoc-RF & $-\left(\mathrm{CH}_{2}\right)_{3}-\mathrm{NH}-\mathrm{C}(\mathrm{NH})-\mathrm{NH}_{2}$ & $-\mathrm{CH}_{2}-\mathrm{Phe}$ \\
\hline Fmoc-CF & $-\mathrm{CH}_{2}-\mathrm{SH}$ & $-\mathrm{CH}_{2}-\mathrm{Phe}$ \\
\hline Fmoc-MF & $-\left(\mathrm{CH}_{2}\right)_{2}-\mathrm{SCH}_{3}$ & $-\mathrm{CH}_{2}-\mathrm{Phe}$ \\
\hline Fmoc-FF & $-\mathrm{CH}_{2}-\mathrm{Phe}$ & $-\mathrm{CH}_{2}-\mathrm{Phe}$ \\
\hline
\end{tabular}


The Fmoc-dipeptide derivatives were co-spread with the DMPA phospholipid in molar ratio 1:1, achieving an initial situation of a mixed monolayer DMPA:Fmoc-dipeptide. This experimental procedure assured the interaction between the components of the Langmuir monolayer, at least prior to compression of the mixed monolayer. ${ }^{39}$ The surface pressure-molecular area isotherms for the DMPA:Fmoc-dipeptide and the pure DMPA monolayers are shown in Figure 2. The isotherms for the mixed monolayers DMPA:Fmoc-GG, DMPA:Fmoc-AA, and DMPA:Fmoc-LG overlap to a large extent with the isotherm for the pure DMPA, thus showing a reduced occupancy of the Fmoc-GG, Fmoc-AA and Fmoc-LG molecules at the DMPA monolayer. Note these Fmocdipeptides show the lowest values of hydrophobicity, see Table 2. The partition coefficient $(P)$ is the ratio of the concentration of a given compound in the organic phase to that in the water phase at infinite dilution, normally reported as $-\log P$, and was calculated according to Robins et al. ${ }^{40}$ The LE expanded phase was suppressed for the isotherms of the DMPA:Fmoc-GG, DMPA:FmocAA, and DMPA:Fmoc-LG mixed monolayers. A relatively small amount of the Fmoc-dipeptide molecules might be present at the mixed monolayers from the expanded state to ca. $0.5 \mathrm{~nm}^{2}$ per DMPA molecule, causing a modification in the physical state of the alkyl chains of the DMPA molecules. While the solid phase of the isotherm was not modified, the region from ca. 0.8 to 0.5 $\mathrm{nm}^{2}$ per DMPA molecule did not display the typical LE phase. The amount of Fmoc-dipeptide molecules at the DMPA monolayer was modest in the three mixed monolayers, as confirmed by UV-vis reflection spectroscopy, see below. Only Fmoc-LG displayed a comparatively higher UVvis reflection signal, probably corresponding to Fmoc-LG adsorbed beneath the DMPA monolayer. Further compression of the monolayers led to a loss of the Fmoc-dipeptides onto the aqueous subphase, probably as micelle-like aggregates. ${ }^{41}$ 
Table 2. Values for partition coefficient $(-\log P)$ of the Fmoc-dipeptide derivatives.

\begin{tabular}{|c|c|}
\hline Fmoc-dipeptide & $-\log \boldsymbol{P}$ \\
\hline FmocGG & 1.37 \\
\hline FmocAA & 2.51 \\
\hline FmocLG & 3.19 \\
\hline FmocRF & 3.91 \\
\hline FmocCF & 4.21 \\
\hline FmocMF & 4.81 \\
\hline FmocFF & 5.82 \\
\hline
\end{tabular}
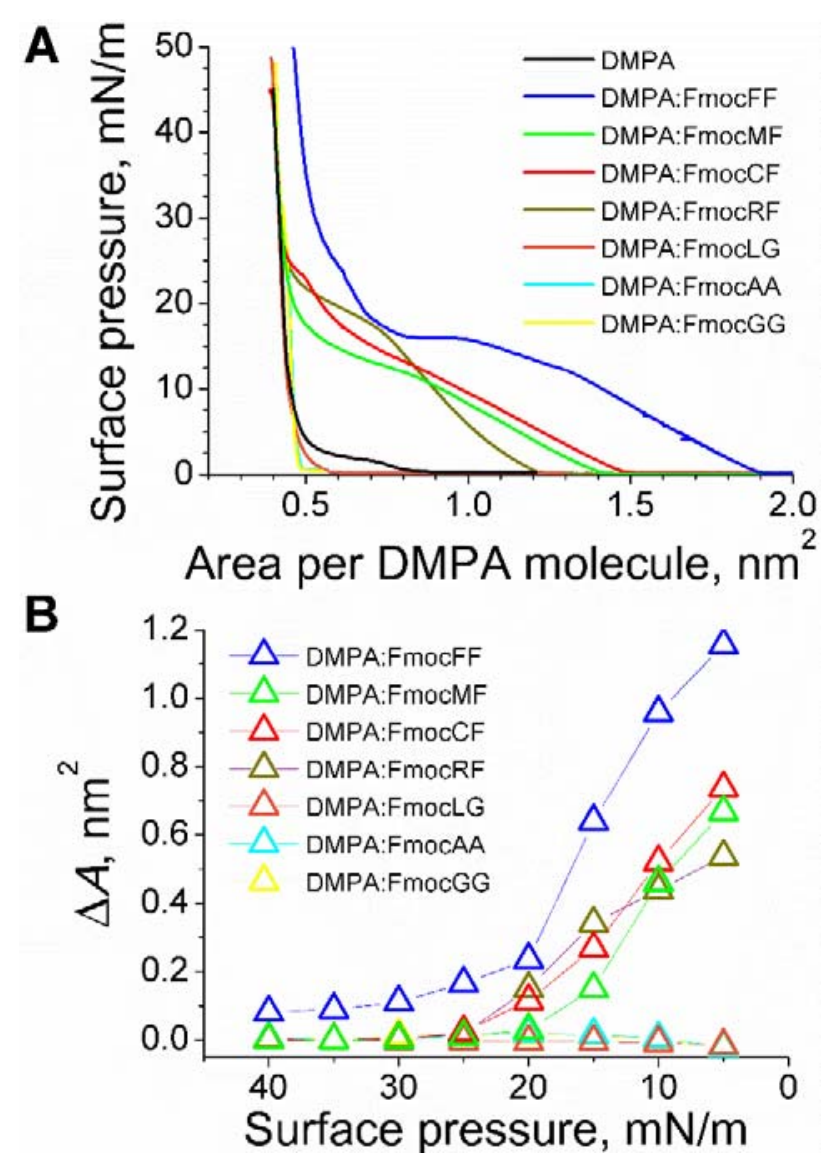

Figure 2. A) Surface pressure-molecular area isotherms for the pure DMPA and the DMPA:Fmocdipeptide mixed monolayers. B) Increment of the molecular area per DMPA molecule of the 
isotherms for the mixed monolayers DMPA:Fmoc-dipeptide with respect to the isotherm for the pure DMPA monolayer.

The surface pressure-molecular area isotherms of the DMPA:Fmoc-dipeptides including a phenyl (F) group show a different behavior to the F-free dipeptides, see Figure 2. Note that the Fcontaining Fmoc-RF, Fmoc-CF, Fmoc-MF, and Fmoc-FF show a higher hydrophobicity. A shift towards larger values of molecular area was obtained for the four F-containing Fmoc-dipeptides in the mixed monolayers at the expanded state. The Fmoc-dipeptide molecules were located at the monolayer for the DMPA:Fmoc-RF, DMPA:Fmoc-CF, and DMPA:Fmoc-MF mixed monolayers as evidenced by the significant lift-off of the surface pressure during the LE-LC transition to values of surface pressure from ca. 18 to $22 \mathrm{mN} / \mathrm{m}$. Further compression of these mixed monolayers above $25 \mathrm{mN} / \mathrm{m}$ led to desorption of the Fmoc-dipeptide molecules onto the subphase. Note that according to the UV-vis reflection spectra (see below), a significant fraction of the Fmoc-dipeptide molecules remained adsorbed underneath the DMPA phospholipid monolayer. Particularly, the DMPA:Fmoc-RF and DMPA:Fmoc-CF monolayers display a significant expansion of their isotherms with respect to the isotherm of pure DMPA for a large interval of the values of surface pressure. Note there are three points of intercrossing between the isotherms of DMPA:Fmoc-RF and DMPA:Fmoc-CF: $0.95 \mathrm{~nm}^{2}$ per DMPA molecule $(12.1 \mathrm{mN} / \mathrm{m}) ; 0.60 \mathrm{~nm}^{2}$ per DMPA molecule $(21.9 \mathrm{mN} / \mathrm{m})$; and $0.56 \mathrm{~nm}^{2}$ per DMPA molecule $(23.7 \mathrm{mN} / \mathrm{m})$. The intercrossing of the isotherms was ascribed to a similar modification in the phase behavior of the DMPA by the Fmoc-dipeptides in a slightly different extent for both Fmoc-RF and Fmoc-CF. ${ }^{42}$ The isotherm for the DMPA:FmocMF monolayer shows an expansion with respect to the isotherm for the pure DMPA similar to those observed for the DMPA:Fmoc-RF and DMPA:Fmoc-CF monolayers indicating the presence 
of the Fmoc-MF at the DMPA monolayer. ${ }^{43}$ Remarkably, the isotherms for DMPA:Fmoc-LG, DMPA:Fmoc-RF, and DMPA:Fmoc-CF converge with isotherm for pure DMPA for surface pressure greater than $25 \mathrm{mN} / \mathrm{m}$. The convergence at high values of surface pressure was related to the expelling of a fraction of the Fmoc-dipeptides from the mixed monolayer onto the subphase. ${ }^{44}$ However, the isotherm for the DMPA:Fmoc-FF monolayer shows the largest deviation with respect to the pure DMPA monolayer.

The DMPA:Fmoc-FF monolayer was the only case for a persistent shift of the isotherm even at high values of surface pressure. Note that the Fmoc-FF dipeptide is the most hydrophobic Fmocdipeptide derivative included in this study. The relative amount of Fmoc-FF molecules could be estimated by considering the shift of the isotherm at high values of surface pressure and an approximate value of the area occupied by a Fmoc-FF molecule in a completely upright arrangement. A value of ca. $0.23 \mathrm{~nm}^{2}$ per Fmoc-FF molecule was obtained using the HyperChem molecular modelling program. ${ }^{45}$ The expansion values of the DMPA:Fmoc-FF isotherm with respect to the pure DMPA isotherm at surface pressure of 20,30 , and $40 \mathrm{mN} / \mathrm{m}$ were $0.24,0.12$, and $0.08 \mathrm{~nm}^{2}$ per DMPA molecule, respectively. These values of shift in the molecular area of the isotherms pointed to an approximate composition of the mixed monolayer DMPA:Fmoc-FF of $1: 1,2: 1$, and $3: 1$ for surface pressure values of 20,30 , and $40 \mathrm{mN} / \mathrm{m}$, respectively. Therefore, the transfer of Fmoc-FF molecules from the mixed monolayer to the subphase led to an enrichment of DMPA in the mixed monolayer up to three-fold at the most compressed state. Remarkably, the amount of Fmoc-FF molecules at the interface increased steadily with the compression of the DMPA:Fmoc-FF mixed monolayer as revealed by UV-vis reflection spectroscopy. Therefore, the interactions between the Fmoc-FF molecules and the DMPA molecules at the phospholipid monolayer were largely favored. 
The influence of the Fmoc-dipeptide molecules on the morphology of the DMPA monolayer at the micrometric level was revealed by in situ Brewster Angle Microscopy (BAM). ${ }^{46-48}$ The DMPA:Fmoc-GG, DMPA:Fmoc-AA, and DMPA:Fmoc-LG monolayers showed a similar behavior, see Figure 3. A rather dense and reflective gas-condensed phase transition plateau was found at the expanded state, indicating the presence of Fmoc-dipeptide molecules interacting with the DMPA at early stages of compression of the mixed monolayers. A fluid phase appeared with a slight increase of surface pressure to 0.5 to $3 \mathrm{mN} / \mathrm{m}$. Such phase was more reflective and dense than the previous gas-condensed phase transition plateau, showing small holes that might correspond to fluid domains of the mixed monolayers. Note that the commonly observed domains of DMPA and related phospholipids were not observed, suggesting the disruption of the liquid expanded-liquid condensed (LE-LC) phase transition of DMPA. ${ }^{49}$ A solid and homogenous phase was formed upon compression of the monolayer. There was a significant effect of the Fmocdipeptide molecules at intermediate values of surface pressure, suppressing the LE-LC phase transition. A certain fraction of the Fmoc-GG, Fmoc-AA, and more significantly Fmoc-LG molecules might remain at the DMPA even at high values of surface pressure. No area was occupied as noted by the isotherms, indicating that the Fmoc-LG molecules were adsorbed underneath the DMPA monolayer as verified by UV-vis reflection spectroscopy, see below. 

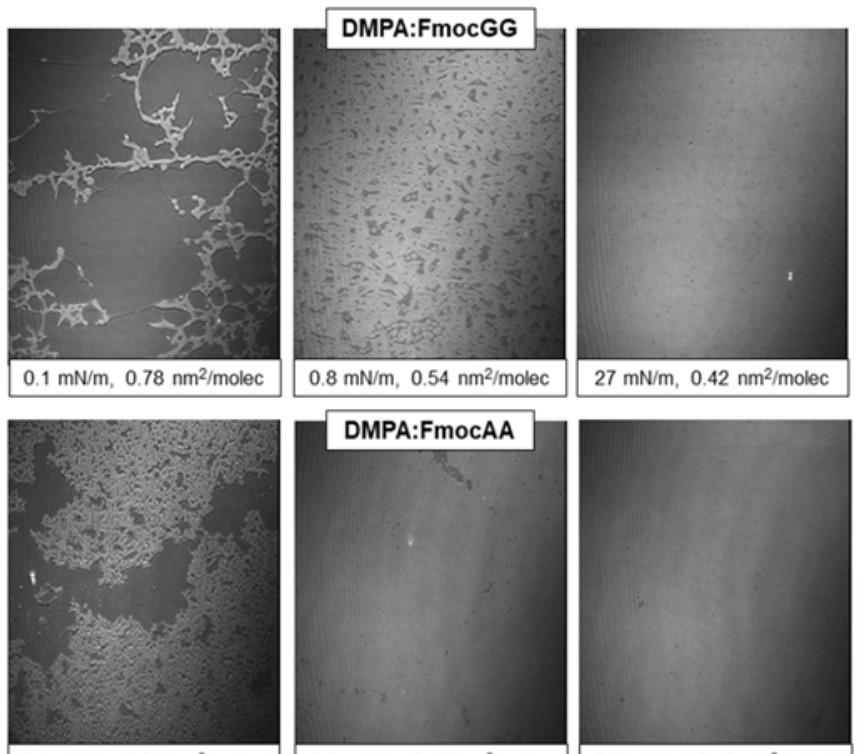

\section{DMPA:FmocAA}

$0.4 \mathrm{mN} / \mathrm{m}, 0.94 \mathrm{~nm}^{2} / \mathrm{molec}$
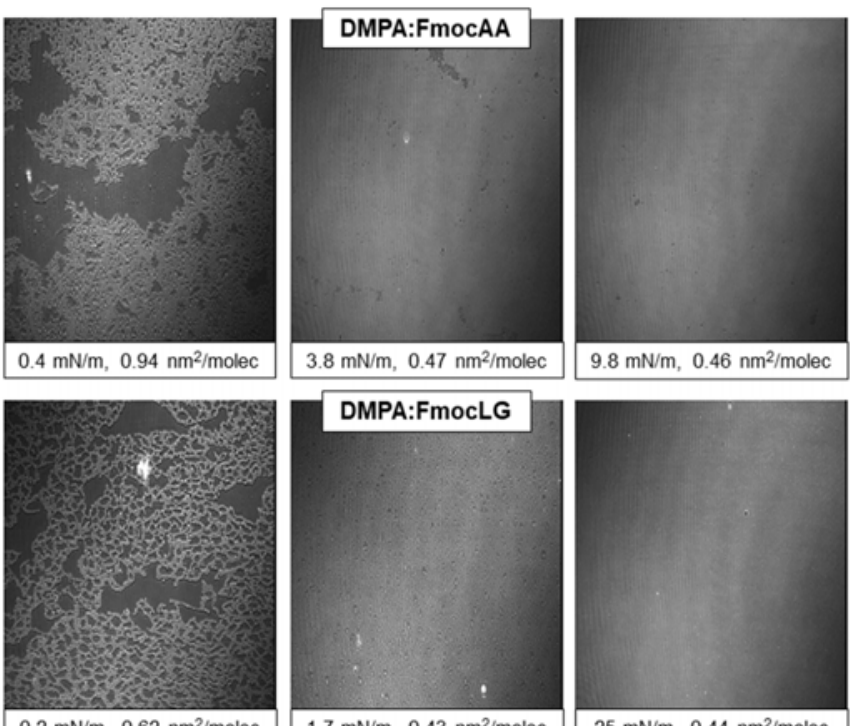

$0.2 \mathrm{mN} / \mathrm{m}, 0.62 \mathrm{~nm}^{2} / \mathrm{molec}$
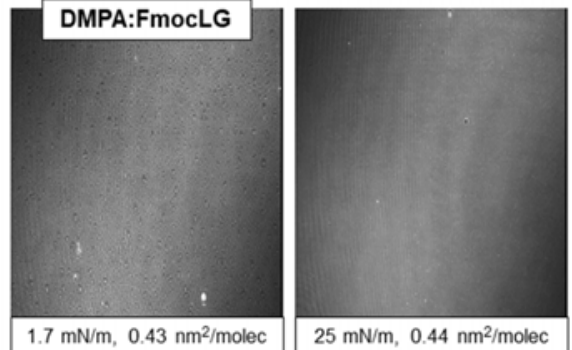

Figure 3. Brewster Angle Microscopy images for the DMPA:Fmoc-GG (top), DMPA:Fmoc-AA (middle), and DMPA:Fmoc-LG (bottom) monolayers. The values of surface pressure and available surface area per DMPA molecule are included at the bottom of each picture. The width of each frame corresponds to $215 \mu \mathrm{m}$.

The DMPA:Fmoc-RF monolayer at highly expanded state displayed a gas-condensed phase transition plateau with some aggregates, see Figure 4. Rounded bright domains during the LE-LC transition were also observed with compression of the monolayer. The domains retained the typical shape for pure DMPA domains, however with higher polydispersity of the size of the domains. The large domains might be composed by pure DMPA in LC state in combination with DMPA and Fmoc-RF. The bright domains reached a more homogeneous size with further compression of 
the monolayer to ca. $43 \mathrm{mN} / \mathrm{m}$, see Figure 4. Note that the background became highly reflective as well, probably related with the presence of the Fmoc-RF molecules.

The DMPA:Fmoc-CF monolayer showed an atypical behavior that was already suggested by the slightly larger shift in the isotherm with respect to DMPA:Fmoc-MF as expected from the lower value of $-\log P$ of Fmoc-CF. A comparatively more reflective gas-condensed phase transition plateau with some defects appearing as rounded dark domains was obtained, see Figure 4. Rounded bright domains for the LE-LC transition were observed, similarly to the DMPA:Fmoc-CF monolayer. A small fraction of elongated microstructures analogous to those formed by pure Fmoc-CF at the air/water interface were also found, with no coalescence with the domains. ${ }^{24}$ An inversion in the phase contrast was obtained upon further compression of the monolayer to a highly compressed state. The more fluid phase surrounding the domains turned brighter than the mentioned domains. Such inversion in the phase contrast was ascribed to an enrichment of the more fluid phase with Fmoc-CF molecules. ${ }^{50}$ This enrichment was promoted by specific interaction between Fmoc-CF molecules: complexation of the cysteine group with neighbor Fmoc groups via $-\mathrm{SH}::: \pi$ electrons in the aromatic rings, with a significant binding energy. ${ }^{51}$ The $-\mathrm{SH}$ group acted as the H-bond donor. This preferential interaction led to the segregation of the more reflective Fmoc-CF molecules out of the DMPA phospholipid domains and therefore to the inversion of the contrast.

Thin and elongated structures were found in the gas-condensed phase transition plateau for the DMPA:Fmoc-MF monolayer, see Figure 4. Bright and regular domains were found during the LE-LC transition at $c a .13 \mathrm{mN} / \mathrm{m}$, analogous to a pure DMPA monolayer. The DMPA domains persisted even at the solid state of the DMPA:Fmoc-MF monolayer, where additional small and highly reflective spots appeared, indicating aggregates of Fmoc-MF, see Figure 4. The inversion 
in phase contrast was not observed in this case, given the methionine group was not able to present the mentioned H-bonding due to the methylene group substituting the hydrogen atom present in the cysteine residue. The presence of Fmoc-CF and Fmoc-MF in the mixed monolayers at high values of surface pressure was further confirmed by UV-vis reflection spectroscopy, see below. BAM informed on the different morphology of the mixed monolayers, disclosing self-aggregated Fmoc-MF and more distributed Fmoc-CF at the mixed monolayers. Note the higher hydrophobicity of Fmoc-MF with respect to Fmoc-CF, leading to superior interaction with the phospholipid monolayer.

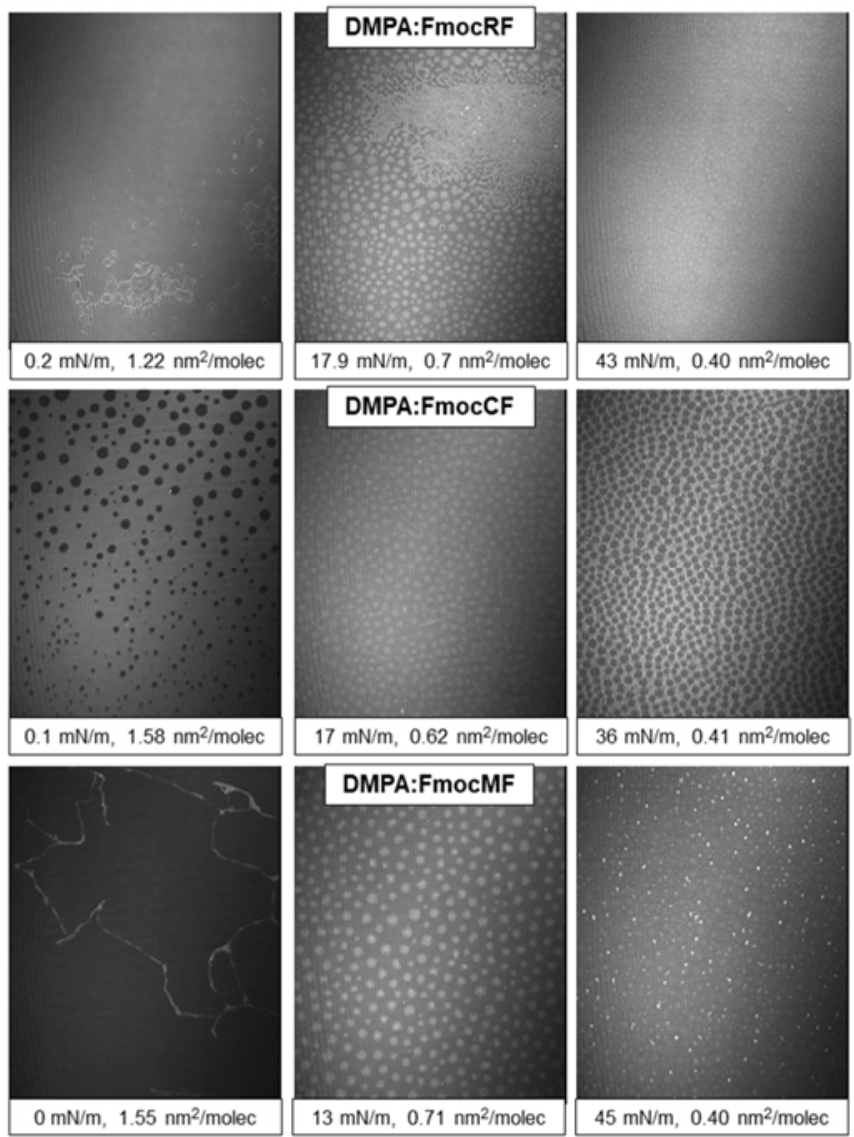

Figure 4. Brewster Angle Microscopy images for the DMPA:Fmoc-RF (top), DMPA:Fmoc-CF (middle), and DMPA:Fmoc-MF (bottom) monolayers. The values of surface pressure and 
available surface area per DMPA molecule are included at the bottom of each picture. The width of each frame corresponds to $215 \mu \mathrm{m}$.

The $\pi-A$ isotherms converge with the pure DMPA isotherm in spite of the significant modification of the morphology observed by BAM. The Fmoc-dipeptide molecules were adsorbed underneath the DMPA monolayer, thus occupying no net area and rendering a significant effect on the BAM images and UV-vis reflection signal. This significant interaction of the mentioned Fmoc-dipeptide derivatives with the DMPA monolayer, already shown in a minor extent by the DMPA:Fmoc-LG monolayer, indicated the suitability of the Fmoc-RF, Fmoc-CF, Fmoc-MF for effective interaction with a phospholipid surface.

The DMPA:Fmoc-FF monolayer displayed a quite different morphology to the mentioned mixed monolayers, see Figure 5. Small aggregates with rounded and elongated shapes were found for the gas-condensed phase transition plateau of the DMPA:Fmoc-FF monolayer. The elongated aggregates persisted along the complete isotherm of the DMPA:Fmoc-FF monolayer, with a significant increase in number and size with compression of the mixed monolayer. These elongated structures are remarkably similar to those obtained for the pure Fmoc-FF spread at the air/water interface. ${ }^{24}$ Note that the number of rounded domains decreased simultaneously to the increase of elongated structures, pointing at a mass transfer of the Fmoc-FF molecules from those domains to the elongated structures. The DMPA domains were not observed for the DMPA:Fmoc-FF monolayer at intermediate values of surface pressure, pointing to a significant distortion of the physical state of the DMPA molecules in the mixed monolayers caused by the Fmoc-FF molecules. Further compression to high values of surface pressure led to aggregation of the elongated structures onto heterogeneous and highly reflective assemblies. The high reflectivity observed by 
BAM was related with a large surface concentration of Fmoc-FF. This observation was consistent with the UV-vis reflection spectroscopy results, see below.
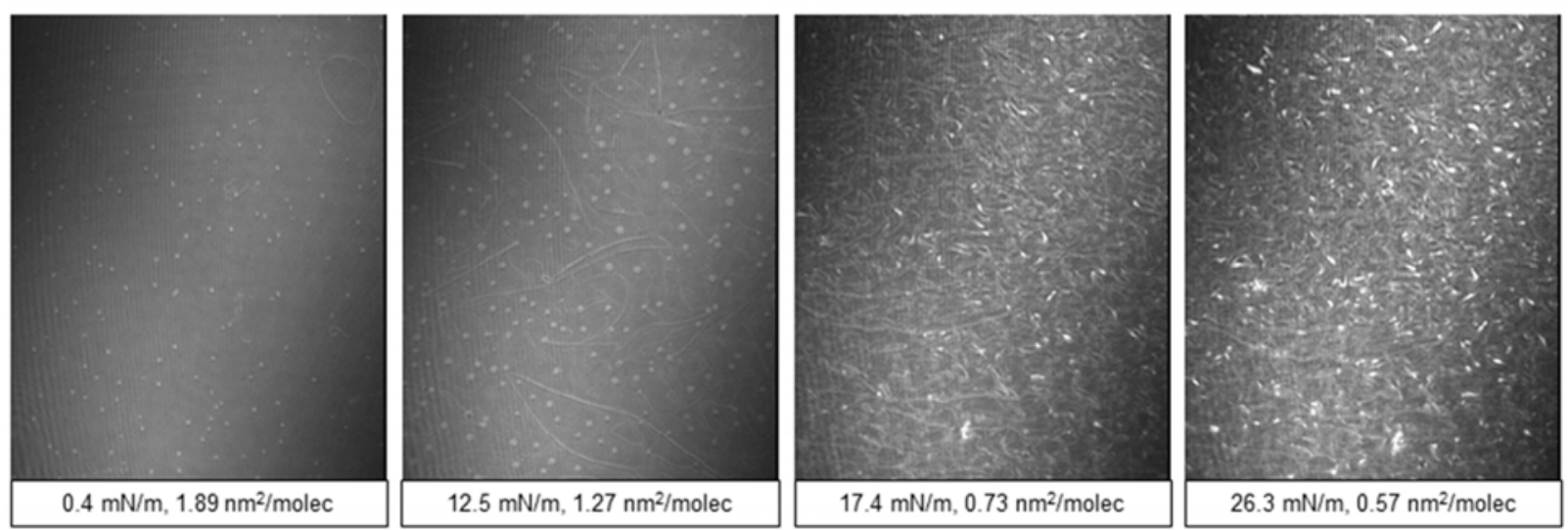

Figure 5. Brewster Angle Microscopy images for the DMPA:Fmoc-FF monolayer. The values of surface pressure and available surface area per DMPA molecule are included at the bottom of each picture. The width of each frame corresponds to $215 \mu \mathrm{m}$.

To gain further insight into the surface concentration of the Fmoc-dipeptide derivatives at the air/water interface, in situ UV-vis reflection spectroscopy was applied. ${ }^{52}$ The UV-vis reflection signal neglects any contribution from the bulk solution, instead arising exclusively from the enhancement of reflection of the incoming radiation by absorbance of molecules located at the air/water interface according to the equation (1):

$$
\Delta R \square 2.303 \cdot 10^{3} f_{0} \varepsilon \sqrt{R_{S}} \Gamma
$$

where $\Delta R$ is the increase of reflection under normal incidence, $\varepsilon$ is the molar absorption coefficient $\left(\mathrm{M}^{-1} \cdot \mathrm{cm}^{-1}\right), R_{\mathrm{S}}$ is the reflectivity of the aqueous interface, $\Gamma$ is the surface concentration $\left(\mathrm{mol} \cdot \mathrm{cm}^{-2}\right)$, and $\mathrm{f}_{0}$ is the orientation factor. 
The Fmoc group displays a significant UV-vis signal. The UV-vis reflection spectra of the DMPA:Fmoc-CF and DMPA:Fmoc-FF as representative examples for the mixed monolayers at different values of molecular area are shown in Figure 6. The UV-vis reflection spectra for the DMPA:Fmoc-CF mixed monolayer showed 4 peaks located at 258, 262, 268, and $283 \mathrm{~nm}$ overlapped into a broad band. Similar spectra were achieved for the DMPA:Fmoc-FF mixed monolayer, showing four bands centred at 257, 262, 270, and $283 \mathrm{~nm}$ with a high extent of overlapping as well. The positions of the bands are similar to those found in self-assembled structures of pure Fmoc-FF at the air/liquid interface. ${ }^{24}$ Therefore, segregation of the Fmocdipeptide and DMPA molecules at the mixed monolayers is expected. This segregation was in agreement with the BAM pictures, in which DMPA domains and elongated reflective structures for the DMPA:Fmoc-CF and DMPA:Fmoc-FF mixed monolayers, respectively. The Fmocdipeptide molecules were located at the mixed monolayers with the Fmoc groups self-arranged in a zipper-like manner.

The UV-vis reflection spectra for the DMPA:Fmoc-CF monolayer lower signal than those for the DMPA:Fmoc-FF monolayer. The absolute value of the UV-vis signal is ca. two-fold greater for the DMPA:Fmoc-FF. Therefore, a higher amount of Fmoc-FF than Fmoc-CF molecules are present at the mixed monolayers, as anticipated from the high reflectivity of the DMPA:Fmoc-FF monolayer observed by BAM, see above. Remarkably, the UV-vis signal did not show a large variation with compression for the DMPA:Fmoc-CF monolayer. A modest variation of the amount of Fmoc-CF molecules with compression was obtained, indicating an expelling of those Fmoc-CF molecules from the mixed monolayer under compression when a steady surface concentration was reached. On the other hand, the UV-vis signal corresponding to the Fmoc-FF molecules increased 
with compression of the monolayer, indicating a significant increase in the surface concentration and the residence of Fmoc-FF molecules at the phospholipid surface.

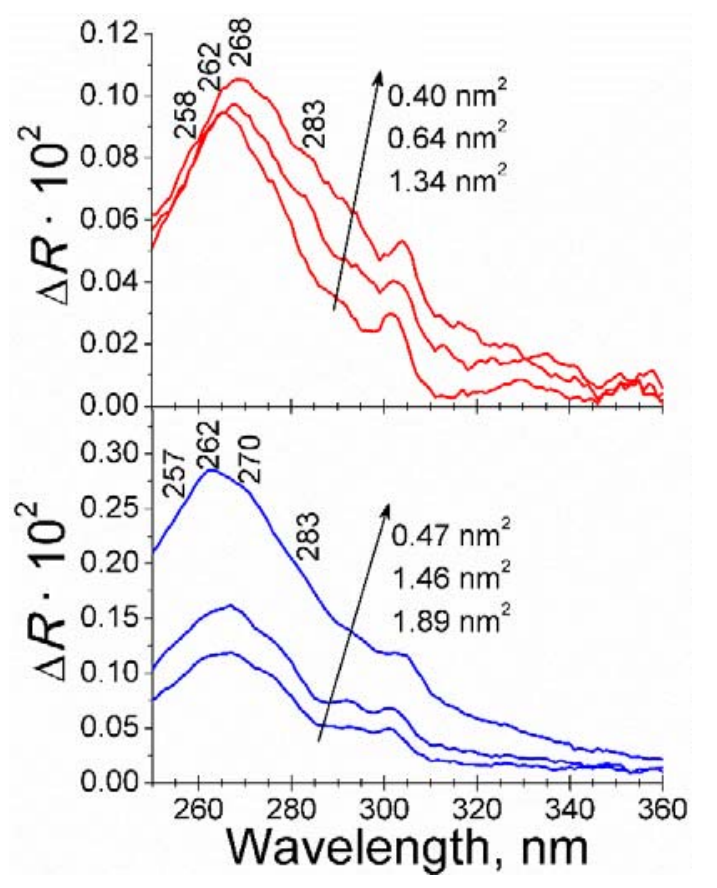

Figure 6. UV-vis reflection for the DMPA:Fmoc-CF (top, red line) and DMPA:Fmoc-FF (bottom, blue line) monolayers. The values of available surface area per DMPA molecule are indicated in the inset. Maximum values of wavelength for each band are indicated in the inset.

The absolute amount of Fmoc-dipeptide molecules at the air/water interface could be monitored by the UV-vis reflection spectra for the DMPA:Fmoc-dipeptide mixed monolayers. Considering the Fmoc group was responsible for the UV-vis signal and all Fmoc-dipeptide derivatives include one Fmoc group per dipeptide molecule, the integrated value of the UV-vis spectra can be directly compared. The integral values of the UV-vis spectra are shown in Figure 7. Considering the high values of available surface area per DMPA molecule, i. e., the expanded state of the monolayers, three groups of DMPA:Fmoc-dipeptide monolayers could be considered. The mixed monolayers containing Fmoc-GG, Fmoc-AA, and Fmoc-LG showed no significant UV-vis signal, pointing to a reduced presence of the Fmoc-dipeptide at the mixed monolayer. This group is formed by the 
less hydrophobic Fmoc-dipeptide derivatives, see Table 2. A second group comprising Fmoc-RF, Fmoc-CF and Fmoc-CF where a significant UV-vis signal was already present even prior to the compression of the mixed monolayers could be defined. A third group was observed solely for the DMPA:Fmoc-FF monolayer, in which the UV-vis signal was ca. two-fold the observed signal or the previous group, thus indicating a comparatively higher content of Fmoc-FF molecules in the mixed monolayer.

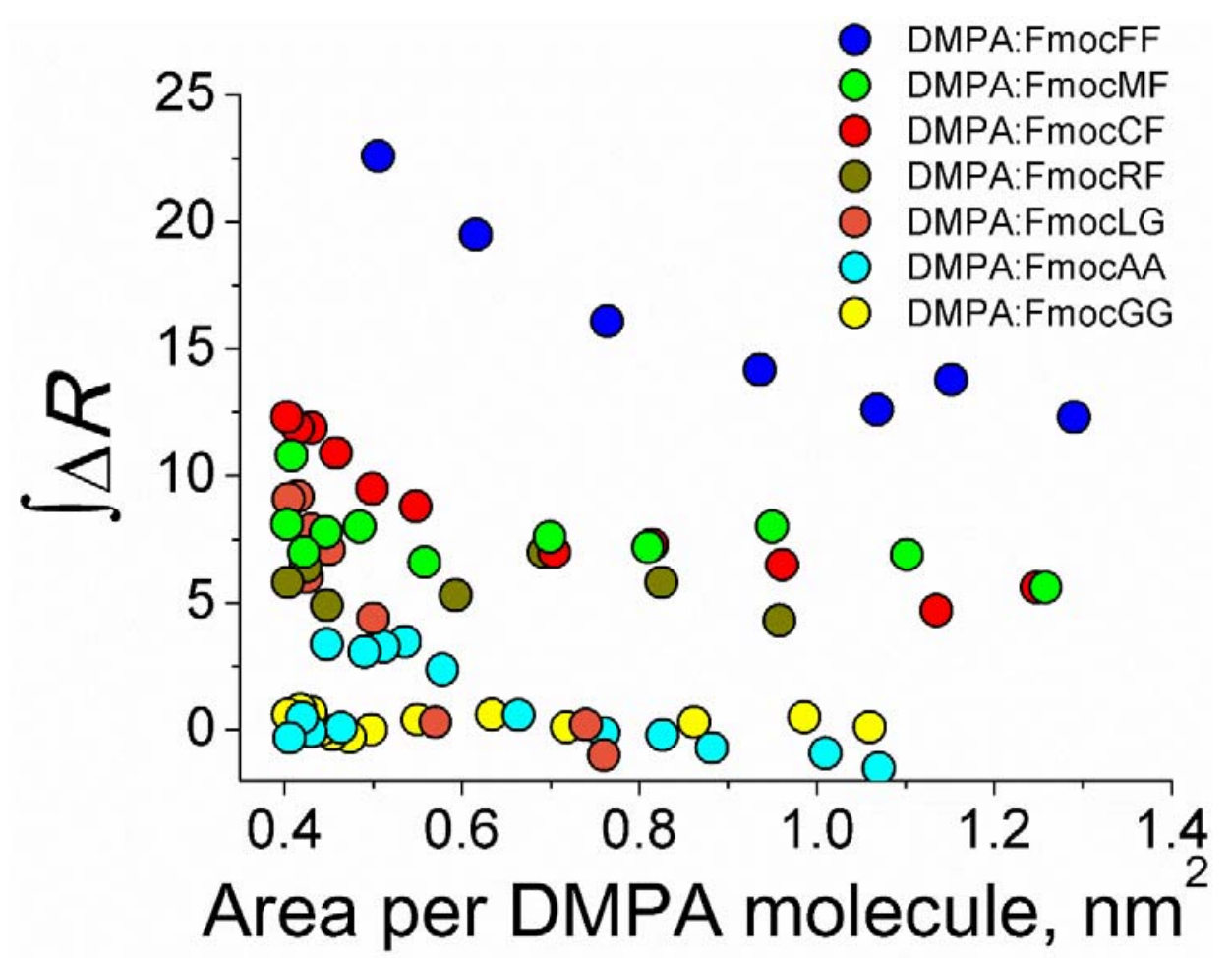

Figure 7. Integral value of the UV-vis spectra for the DMPA:Fmoc dipeptide derivatives at different values of available surface area per DMPA molecule. Composition of the mixed monolayers as noted in the inset. 
Different trends were observed with compression of the mixed monolayers. Concerning the first group of hydrophilic dipeptides, no signal was attained from the mixed monolayers containing Fmoc-GG and Fmoc-AA. This result was in agreement with the expected solubilization of the Fmoc-dipeptide molecules onto the aqueous subphase. However, a significant increase of the UVvis signal is obtained for the Fmoc-LG in contact with a highly compressed DMPA monolayer, indicating the partition of the Fmoc-LG molecules from the aqueous subphase to the DMPA monolayer when the phospholipid molecules provide enough surface to interact.

A constant value for the UV-vis reflection signal was obtained for the mixed monolayers of the more hydrophobic second group of Fmoc-dipeptides, with a modest increase at the highly compressed state of the mixed monolayer. Despite this increase of surface concentration of Fmocdipeptide molecules at the highest surface pressure, the intensity of the UV-vis signal remained almost constant for most of the isotherm. The relative fraction of the Fmoc-RF, Fmoc-CF, and Fmoc-MF molecules was in a steady state along compression, in which the accumulation of Fmocdipeptide molecules by compression of the monolayer is compensated by a certain solubilization onto the aqueous subphase.

An increase of the UV-vis reflection signal with the compression of the DMPA:Fmoc-FF monolayer was registered, pointing to a steady enrichment in Fmoc-FF molecules. This enrichment was related to the decrease in the available surface area with reduced or no solubilization of the Fmoc-FF molecules into the aqueous subphase. The residence of the Fmoc-FF molecules at the DMPA:Fmoc-FF mixed monolayers was therefore superior to the other Fmoc-dipeptide derivatives, as expected from the highest value of $-\log P$. This increase of amount of Fmoc-FF molecules interacting with the DMPA molecules with a relative increase of the hydrophobicity 
was in agreement with the study on oligopeptides with phospholipid mono- and bi-layers by Blume et al. ${ }^{53}$

The evolution of the surface concentration of the Fmoc-dipeptide molecules with the compression of the mixed monolayers could be elucidated following the UV-vis reflection signal normalized by the DMPA surface area, as described by equation (2) considering $A_{\mathrm{DMPA}}$ the available surface area per DMPA molecule and $\mathrm{N}_{\mathrm{A}}$ as the Avogadro number:

$$
\Delta R_{\text {norm }}=A_{D M P A} \times \Delta R=\frac{2.303 \times 10^{17} f_{0} \varepsilon}{N_{\mathrm{A}}} \sqrt{R_{\mathrm{S}}}=5.41 \times 10^{-8} f_{0} \varepsilon
$$

The integrated values of the normalized UV-vis signal for the mixed monolayers containing the Fmoc-CF, Fmoc-MF, and Fmoc-FF are shown in Figure 8.

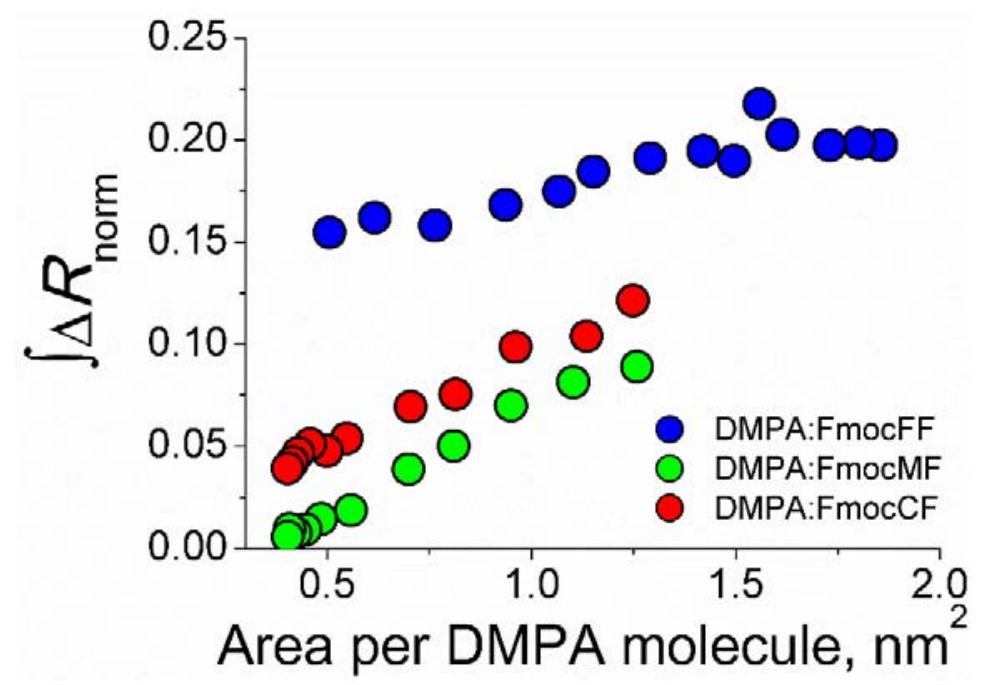

Figure 8. Integral value of the normalized UV-vis spectra at different values of available surface area per DMPA molecule for the DMPA:FmocFF, DMPA:FmocMF, and DMPA:FmocCF as noted in the inset. 
The DMPA:Fmoc-CF and DMPA:Fmoc-MF monolayers showed a similar behavior, with a $c a$. $25 \%$ of the UV-vis reflection intensity remaining from the initial UV-vis reflection intensity after complete compression of the mixed monolayers. This observation agrees with the previous finding on the Fmoc-CF and Fmoc-MF molecules being expelled to the aqueous subphase in a certain fraction with compression of the mixed monolayers. On the other hand, a ca. $80 \%$ of the UV-vis reflection intensity remained from the initial UV-vis reflection intensity after compression from $1.25 \mathrm{~nm}^{2}$ to $0.7 \mathrm{~nm}^{2}$ per DMPA molecule. Note that the surface concentration of Fmoc-FF appeared as almost constant for the final interval of the isotherm from $0.7 \mathrm{~nm}^{2}$ to $0.5 \mathrm{~nm}^{2}$ per DMPA molecule. The discrepancy with the surface pressure-molecular area isotherm was ascribed to a phase transition in the mixed monolayer for the large area range considered. The persistence of the Fmoc-FF molecules even in a highly compressed monolayer was therefore confirmed. This observation is also in agreement with the observed increase of DMPA molecular area in the surface pressure-molecular area isotherm at high values of surface pressure. From these data we could conclude that high hydrophobicity led to a strong interfacial self-assembly of the Fmoc-FF molecules prevailing over the interactions with the DMPA molecules. The persistent presence of these self-assembled structures was able to significantly distort the DMPA phospholipid layer. Indeed, Laverty et al. proposed that the hydrophobic interactions promoted by aromatic groups in Fmoc-FF with phospholipids composing the membrane of erythrocytes could lead to a significant toxicity shown in significant hemolysis during in vitro experiments. ${ }^{54}$

Therefore, the aminoacid sequence determines the hydrophobicity/hydrophilic balance in Fmocdipeptide derivatives, which in turn controls the interaction with the phospholipid surface. By adjusting the hydrophobicity of the Fmoc-dipeptide derivatives, the tuning of the interactions of the Fmoc-dipeptide molecules with the DMPA phospholipid surface has been demonstrated here. 
There was no linear or easily predicted trend of the extent of interaction of the Fmoc-dipeptide molecules with the phospholipid monolayer with the values of $-\log P$. Instead, three types of behavior could be found, see Table 3 .

Table 3. Summary of the interactions of the Fmoc-dipeptide derivatives with a model membrane as a function of $-\log P$.

\begin{tabular}{|c|c|c|c|}
\hline - $\log P$ & $\begin{array}{c}\text { Amino acid } \\
\text { sequence for the } \\
\text { Fmoc-dipeptide }\end{array}$ & Effect on a model cell surface & $\begin{array}{c}\text { Expected biological } \\
\text { activity }\end{array}$ \\
\hline 1.37 to 3.19 & $\begin{array}{c}\text { FmocGG, FmocAA, } \\
\text { FmocLG }\end{array}$ & $\begin{array}{c}\text { Low or no adsorption along the } \\
\text { isotherm }\end{array}$ & $\begin{array}{c}\text { Reduced or no } \\
\text { interaction with } \\
\text { living cells }\end{array}$ \\
\hline 3.91 to 4.81 & $\begin{array}{c}\text { FmocRF, FmocCF, } \\
\text { FmocMF }\end{array}$ & $\begin{array}{c}\text { Significant interactions at low } \\
\text { values of surface pressure and } \\
\text { adsorption at high values of } \\
\text { surface pressure }\end{array}$ & $\begin{array}{c}\text { Significant } \\
\text { interactions with } \\
\text { living cells with no } \\
\text { disruption of the } \\
\text { membrane, "safety } \\
\text { zone" }\end{array}$ \\
\hline 5.82 & FmocFF & $\begin{array}{c}\text { Fmoc-dipeptide and significant } \\
\text { disruption of the lipid } \\
\text { monolayer at all values of } \\
\text { surface pressure }\end{array}$ & $\begin{array}{c}\text { Persistent presence of the } \\
\text { Disruption of cell } \\
\text { membrane }\end{array}$ \\
\hline
\end{tabular}

While hydrophilic Fmoc-dipeptides did not show significant interaction with the DMPA phospholipid monolayer, an excess of hydrophobicity might lead to predominance of selfassembly of Fmoc-dipeptides at the phospholipid monolayer, ultimately showing toxicity. A "safety zone" for Fmoc-dipeptide derivatives that present efficient interaction with the phospholipid surface while avoiding toxicity has been defined in the interval of $-\log P$ from ca. 4 to 5. The interval corresponded to the Fmoc-RF, Fmoc-CF, and Fmoc-MF from this set of Fmoc- 
dipeptides. This study aimed to provide a semiquantitative guide on the hydrophobicity/hydrophilicity balance that might allow an efficient interaction with the phospholipid surface at cell membranes and therefore an optimal performance for biological applications.

\section{CONCLUSIONS}

The interactions between a set of Fmoc-dipeptide derivatives with a broad range of hydrophobicity with a DMPA phospholipid surface as model of cell membrane have been assessed. Less hydrophobic Fmoc-dipeptide molecules are expelled from the model surface, instead occupying the bulk aqueous phase. With the gradual increase of hydrophobicity, the interactions between the Fmoc-dipeptides and the DMPA molecules are enhanced, leading to an improved residence of the Fmoc-dipeptide molecules at the mixed monolayers. Comparatively hydrophilic Fmoc-dipeptide suppressed the LE expanded phase of the DMPA phospholipid. A greater modification of the physical state of the DMPA phospholipid molecules at the mixed monolayer with hydrophobic Fmoc-dipeptide derivatives was also observed. A significant fraction of the Fmoc-dipeptide molecules remained adsorbed underneath the DMPA phospholipid monolayer. However, a severe alteration of the DMPA phospholipid molecules has been observed for the DMPA:Fmoc-FF mixed monolayer, thus pointing to the toxic effect of the highly hydrophobic Fmoc-FF as a result of such interactions. The shift in the molecular area of the isotherms pointed to an approximate composition of the mixed monolayer DMPA:Fmoc-FF from 1:1 to $3: 1$ for surface pressure from 20 to $40 \mathrm{mN} / \mathrm{m}$. Besides additional suitable chemical modifications, the phenyl group in the aminoacid residues appeared as a relevant chemical group for tuning the hydrophobic/hydrophilic balance. This study provides insights for a semiquantitative 
range of hydrophobicity in the chemical design of Fmoc-dipeptides for biologically related applications.

\section{AUTHOR INFORMATION}

\section{Corresponding Author}

lac@ugr.es (L. A.-C.), jjginer@uco.es (J. J. G.-C.)

\section{Author Contributions}

The manuscript was written through contributions of all authors. All authors have given approval to the final version of the manuscript.

\section{ACKNOWLEDGMENT}

Support from the Ministry of Economy and Competitiveness of Spain through the MANA project CTQ2017-83961-R is acknowledged. FIS2017-85954-R (Agencia Estatal de Investigación, AEI, Spain, co-funded by Fondo Europeo de Desarrollo Regional, ERDF, European Union). J.J.G.-C. acknowledges the Ministry of Economy and Competitiveness for a "Ramon y Cajal” contract (RyC-2014-14956).

\section{REFERENCES}

(1) Li, S.; Zou, Q.; Li, Y.; Yuan, C.; Xing, R.; Yan, X. Smart Peptide-Based Supramolecular Photodynamic Metallo-Nanodrugs Designed by Multicomponent Coordination SelfAssembly. J. Am. Chem. Soc. 2018, 140 (34), 10794-10802.

(2) Anami, Y.; Yamazaki, C. M.; Xiong, W.; Gui, X.; Zhang, N.; An, Z.; Tsuchikama, K. Glutamic Acid-valine-citrulline Linkers Ensure Stability and Efficacy of Antibody-drug 
Conjugates in Mice. Nat. Commun. 2018, 9 (1), 2512.

(3) Baral, A.; Roy, S.; Dehsorkhi, A.; Hamley, I. W.; Mohapatra, S.; Ghosh, S.; Banerjee, A. Assembly of an Injectable Noncytotoxic Peptide-Based Hydrogelator for Sustained Release of Drugs. Langmuir 2014, 30 (3), 929-936.

(4) Feng, Z.; Wang, H.; Xu, B. Instructed Assembly of Peptides for Intracellular Enzyme Sequestration. J. Am. Chem. Soc. 2018, 140 (48), 16433-16437.

(5) Katsoulidis, A. P.; Antypov, D.; Whitehead, G. F. S.; Carrington, E. J.; Adams, D. J.; Berry, N. G.; Darling, G. R.; Dyer, M. S.; Rosseinsky, M. J. Chemical Control of Structure and Guest Uptake by a Conformationally Mobile Porous Material. Nature 2019, 565 (7738), $213-217$.

(6) Paramonov, S. E.; Jun, H.-W.; Hartgerink, J. D. Self-Assembly of Peptide-Amphiphile Nanofibers: The Roles of Hydrogen Bonding and Amphiphilic Packing. J. Am. Chem. Soc. 2006, 128 (22), 7291-7298.

(7) Mozhdehi, D.; Luginbuhl, K. M.; Simon, J. R.; Dzuricky, M.; Berger, R.; Varol, H. S.; Huang, F. C.; Buehne, K. L.; Mayne, N. R.; Weitzhandler, I.; et al. Genetically Encoded Lipid-polypeptide Hybrid Biomaterials That Exhibit Temperature-Triggered Hierarchical Self-Assembly. Nat. Chem. 2018, 10 (5), 496-505.

(8) Sánchez-Ferrer, A.; Adamcik, J.; Handschin, S.; Hiew, S. H.; Miserez, A.; Mezzenga, R. Controlling Supramolecular Chiral Nanostructures by Self-Assembly of a Biomimetic $\beta$ Sheet-Rich Amyloidogenic Peptide. ACS Nano 2018, 12 (9), 9152-9161. 
(9) Fleming, S.; Debnath, S.; Frederix, P. W. J. M.; Tuttle, T.; Ulijn, R. V. Aromatic Peptide Amphiphiles: Significance of the Fmoc Moiety. Chem. Commun. 2013, 49 (90), 10587.

(10) Yang, D.; Duan, P.; Zhang, L.; Liu, M. Chirality and Energy Transfer Amplified Circularly Polarized Luminescence in Composite Nanohelix. Nat. Commun. 2017, 8, 15727.

(11) Mansbach, R. A.; Ferguson, A. L. Patchy Particle Model of the Hierarchical Self-Assembly of $\pi$-Conjugated Optoelectronic Peptides. J. Phys. Chem. B 2018, 122 (44), 10219-10236.

(12) McDougall, L.; Draper, E. R.; Beadle, J. D.; Shipman, M.; Raubo, P.; Jamieson, A. G.; Adams, D. J. Enzymatically-Stable Oxetane-Based Dipeptide Hydrogels. Chem. Commun. 2018, 54 (14), 1793-1796.

(13) Debnath, S.; Shome, A.; Das, D.; Das, P. K. Hydrogelation Through Self-Assembly of Fmoc-Peptide Functionalized Cationic Amphiphiles: Potent Antibacterial Agent. J. Phys. Chem. B 2010, 114 (13), 4407-4415.

(14) Wang, H.; Feng, Z.; Xu, B. D-Amino Acid-Containing Supramolecular Nanofibers for Potential Cancer Therapeutics. Adv. Drug Deliv. Rev. 2017, 110-111, 102-111.

(15) Avitabile, C.; Diaferia, C.; Della Ventura, B.; Mercurio, F. A.; Leone, M.; Roviello, V.; Saviano, M.; Velotta, R.; Morelli, G.; Accardo, A.; et al. Self-Assembling of Fmoc-GC Peptide Nucleic Acid Dimers into Highly Fluorescent Aggregates. Chem. Eur. J. 2018, 24 (18), 4729-4735.

(16) Kulkarni, K.; Hung, J.; Fulcher, A. J.; Chan, A. H. P.; Hong, A.; Forsythe, J. S.; Aguilar, M.-I.; Wise, S. G.; Del Borgo, M. P. $\beta 3$-Tripeptides Coassemble into Fluorescent Hydrogels 
for Serial Monitoring in Vivo. ACS Biomater. Sci. Eng. 2018, 4 (11), 3843-3847.

(17) González-Díaz, N. E.; López-Rendón, R.; Ireta, J. Insight Into the Dipeptide Self-Assembly Process Using Density Functional Theory. J. Phys. Chem. C 2019, 123 (4), 2526-2532.

(18) Fu, M.; Li, Q.; Sun, B.; Yang, Y.; Dai, L.; Nylander, T.; Li, J. Disassembly of Dipeptide Single Crystals Can Transform the Lipid Membrane into a Network. ACS Nano 2017, 11 (7), 7349-7354.

(19) Wei, C.; Pohorille, A. Sequence-Dependent Interfacial Adsorption and Permeation of Dipeptides across Phospholipid Membranes. J. Phys. Chem. B 2017, 121 (42), 9859-9867.

(20) Uyaver, S.; Hernandez, H. W.; Habiboglu, M. G. Self-Assembly of Aromatic Amino Acids: A Molecular Dynamics Study. Phys. Chem. Chem. Phys. 2018, 20 (48), 30525-30536.

(21) Yang, H.; Wang, Q.; Li, Z.; Li, F.; Wu, D.; Fan, M.; Zheng, A.; Huang, B.; Gan, L.; Zhao, Y.; et al. Hydrophobicity-Adaptive Nanogels for Programmed Anticancer Drug Delivery. Nano Lett. 2018, 18 (12), 7909-7918.

(22) Yang, B.; Adams, D. J.; Marlow, M.; Zelzer, M. Surface-Mediated Supramolecular SelfAssembly of Protein, Peptide, and Nucleoside Derivatives: From Surface Design to the Underlying Mechanism and Tailored Functions. Langmuir 2018, 34 (50), 15109-15125.

(23) Adams, D. J.; Mullen, L. M.; Berta, M.; Chen, L.; Frith, W. J. Relationship between Molecular Structure, Gelation Behaviour and Gel Properties of Fmoc-Dipeptides. Soft Matter 2010, 6 (9), 1971.

(24) Argudo, P. G.; Contreras-Montoya, R.; Álvarez de Cienfuegos, L.; Cuerva, J. M.; Cano, M.; 
Alba-Molina, D.; Martín-Romero, M. T.; Camacho, L.; Giner-Casares, J. J. Unravelling the 2D Self-Assembly of Fmoc-Dipeptides at Fluid Interfaces. Soft Matter 2018, 14 (46), 93439350.

(25) Giner-Casares, J. J.; Brezesinski, G.; Möhwald, H. Langmuir Monolayers as Unique Physical Models. Curr. Opin. Colloid Interface Sci. 2014, 19 (3), 176-182.

(26) Benedini, L. A.; Sequeira, M. A.; Fanani, M. L.; Maggio, B.; Dodero, V. I. Development of a Nonionic Azobenzene Amphiphile for Remote Photocontrol of a Model Biomembrane. J. Phys. Chem. B 2016, 120 (17), 4053-4063.

(27) Lopes, D.; Nunes, C.; Fontaine, P.; Sarmento, B.; Reis, S. Proof of Pore Formation and Biophysical Perturbations through a 2D Amoxicillin-Lipid Membrane Interaction Approach. Biochim. Biophys. Acta, Biomembr. 2017, 1859 (5), 803-812.

(28) Cruz Gomes da Silva, R. L.; Oliveira da Silva, H. F.; da Silva Gasparotto, L. H.; Caseli, L. How the Interaction of PVP-Stabilized Ag Nanoparticles with Models of Cellular Membranes at the Air-Water Interface Is Modulated by the Monolayer Composition. $J$. Colloid Interface Sci. 2018, 512, 792-800.

(29) Bettini, S.; Pagano, R.; Borovkov, V.; Giancane, G.; Valli, L. The Role of the Central Metal Ion of Ethane-Bridged Bis-Porphyrins in Histidine Sensing. J. Colloid Interface Sci. 2019, $533,762-770$.

(30) De Zotti, M.; Muzzi, B.; Gatto, E.; Di Napoli, B.; Mazzuca, C.; Palleschi, A.; Placidi, E.; Formaggio, F.; Toniolo, C.; Venanzi, M. Tuning the Morphology of Nanostructured Peptide Films by the Introduction of a Secondary Structure Conformational Constraint: A Case 
Study of Hierarchical Self-Assembly. J. Phys. Chem. B 2018, 122 (24), 6305-6313.

(31) Li, T.; Kalloudis, M.; Cardoso, A. Z.; Adams, D. J.; Clegg, P. S. Drop-Casting Hydrogels at a Liquid Interface: The Case of Hydrophobic Dipeptides. Langmuir 2014, 30 (46), $13854-13860$.

(32) Vijay, R.; Polavarapu, P. L. Fmoc-Amino Acid Surfactants: Discovery, Characterization and Chiroptical Spectroscopy. J. Phys. Chem. A 2012, 116 (44), 10759-10769.

(33) Teixeira, R.; Andrade, S. M.; Vaz Serra, V.; Paulo, P. M. R.; Sánchez-Coronilla, A.; Neves, M. G. P. M. S.; Cavaleiro, J. A. S.; Costa, S. M. B. Reorganization of Self-Assembled Dipeptide Porphyrin J-Aggregates in Water-Ethanol Mixtures. J. Phys. Chem. B 2012, 116 (8), 2396-2404.

(34) Tao, K.; Levin, A.; Adler-Abramovich, L.; Gazit, E. Fmoc-Modified Amino Acids and Short Peptides: Simple Bio-Inspired Building Blocks for the Fabrication of Functional Materials. Chem. Soc. Rev. 2016, 45 (14), 3935-3953.

(35) Pott, T.; Maillet, J. C.; Dufourc, E. J. Effects of PH and Cholesterol on DMPA Membranes: A Solid State 2H- and 31P-NMR Study. Biophys. J. 1995, 69 (5), 1897-1908.

(36) Zhang, T.; Brantley, S. L.; Verreault, D.; Dhankani, R.; Corcelli, S. A.; Allen, H. C. Effect of PH and Salt on Surface p K a of Phosphatidic Acid Monolayers. Langmuir 2018, 34 (1), $530-539$.

(37) Goto, T. E.; Lopes, C. C.; Nader, H. B.; Silva, A. C. A.; Dantas, N. O.; Siqueira, J. R.; Caseli, L. CdSe Magic-Sized Quantum Dots Incorporated in Biomembrane Models at the 
Air-water Interface Composed of Components of Tumorigenic and Non-Tumorigenic Cells. Biochim. Biophys. Acta, Biomembr. 2016, 1858 (7), 1533-1540.

(38) Griffith, E. C.; Perkins, R. J.; Telesford, D.-M.; Adams, E. M.; Cwiklik, L.; Allen, H. C.; Roeselová, M.; Vaida, V. Interaction of l-Phenylalanine with a Phospholipid Monolayer at the Water-Air Interface. J. Phys. Chem. B 2015, 119 (29), 9038-9048.

(39) Hädicke, A.; Schwieger, C.; Blume, A. Cospreading of Anionic Phospholipids with Peptides of the Structure (KX) $4 \mathrm{~K}$ at the Air-Water Interface: Influence of Lipid Headgroup Structure and Hydrophobicity of the Peptide on Monolayer Behavior. Langmuir 2017, 33 (43), 12204-12217.

(40) Viswanadhan, V. N.; Ghose, A. K.; Revankar, G. R.; Robins, R. K. Atomic Physicochemical Parameters for Three Dimensional Structure Directed Quantitative Structure-Activity Relationships. 4. Additional Parameters for Hydrophobic and Dispersive Interactions and Their Application for an Automated Superposition of Certain. J. Chem. Inf. Model. 1989, 29 (3), 163-172.

(41) Draper, E. R.; Su, H.; Brasnett, C.; Poole, R. J.; Rogers, S.; Cui, H.; Seddon, A.; Adams, D. J. Opening a Can of Worm(-like Micelle)s: The Effect of Temperature of Solutions of Functionalized Dipeptides. Angew. Chem. Int. Ed. 2017, 129 (35), 10603-10606.

(42) Fidalgo Rodríguez, J. L.; Dynarowicz-Latka, P.; Miñones Conde, J. Effects of Saturated and Polyunsaturated Fatty Acids on Interactions with Cholesterol versus 7-Ketocholesterol in Langmuir Monolayers and Their Potential Biological Implications. Colloids Surf., B 2018, 174, 189-198. 
(43) Nunes, C.; Brezesinski, G.; Lopes, D.; Lima, J. L. F. C.; Reis, S.; Lúcio, M. Lipid-Drug Interaction: Biophysical Effects of Tolmetin on Membrane Mimetic Systems of Different Dimensionality. J. Phys. Chem. B 2011, 115 (43), 12615-12623.

(44) Tuccitto, N.; Amato, T.; Gangemi, C. M. A.; Trusso Sfrazzetto, G.; Puglisi, R.; Pappalardo, A.; Ballistreri, F. P.; Messina, G. M. L.; Li-Destri, G.; Marletta, G. Driving Coordination Polymer Monolayer Formation by Competitive Reactions at the Air/Water Interface. Langmuir 2018, 34 (39), 11706-11713.

(45) HyperChem 7.5. Hypercube (2003).

(46) Fanani, M. L.; Busto, J. V.; Sot, J.; Abad, J. L.; Fabrías, G.; Saiz, L.; Vilar, J. M. G.; Goñi, F. M.; Maggio, B.; Alonso, A. Clearly Detectable, Kinetically Restricted Solid-Solid Phase Transition in Cis -Ceramide Monolayers. Langmuir 2018, 34 (39), 11749-11758.

(47) Alves, A. C.; Nunes, C.; Lima, J.; Reis, S. Daunorubicin and Doxorubicin Molecular Interplay with 2D Membrane Models. Colloids Surf., B 2017, 160, 610-618.

(48) Wojcik, A.; Pawłowski, M.; Wydro, P.; Broniatowski, M. Effects of Polychlorinated Pesticides and Their Metabolites on Phospholipid Organization in Model Microbial Membranes. J. Phys. Chem. B 2018, 122 (50), 12017-12030.

(49) Aroti, A.; Leontidis, E.; Maltseva, E.; Brezesinski, G. Effects of Hofmeister Anions on DPPC Langmuir Monolayers at the Air-Water Interface. J. Phys. Chem. B 2004, 108 (39), $15238-15245$.

(50) Roldán-Carmona, C.; Giner-Casares, J. J.; Pérez-Morales, M.; Martín-Romero, M. T.; 
Camacho, L. Revisiting the Brewster Angle Microscopy: The Relevance of the Polar Headgroup. Adv. Colloid Interface Sci. 2012, 173, 12-22.

(51) Biswal, H. S.; Wategaonkar, S. Sulfur, Not Too Far Behind O, N, and C: SH $\cdots \pi$ Hydrogen Bond. J. Phys. Chem. A 2009, 113 (46), 12774-12782.

(52) Rubia-Payá, C.; De Miguel, G.; Martín-Romero, M. T.; Giner-Casares, J. J.; Camacho, L. UV-Vis Reflection-Absorption Spectroscopy at Air-Liquid Interfaces. Adv. Colloid Interface Sci. 2015, 225, 134-145.

(53) Hädicke, A.; Blume, A. Interaction of Short Pentavalent Cationic Peptides with Negatively Charged DPPG Monolayers and Bilayers: Influence of Peptide Modifications on Binding. J. Phys. Chem. B 2018, 122 (46), 10522-10534.

(54) McCloskey, A. P.; Draper, E. R.; Gilmore, B. F.; Laverty, G. Ultrashort Self-Assembling Fmoc-Peptide Gelators for Anti-Infective Biomaterial Applications. J. Pept. Sci. 2017, 23 (2), 131-140. 


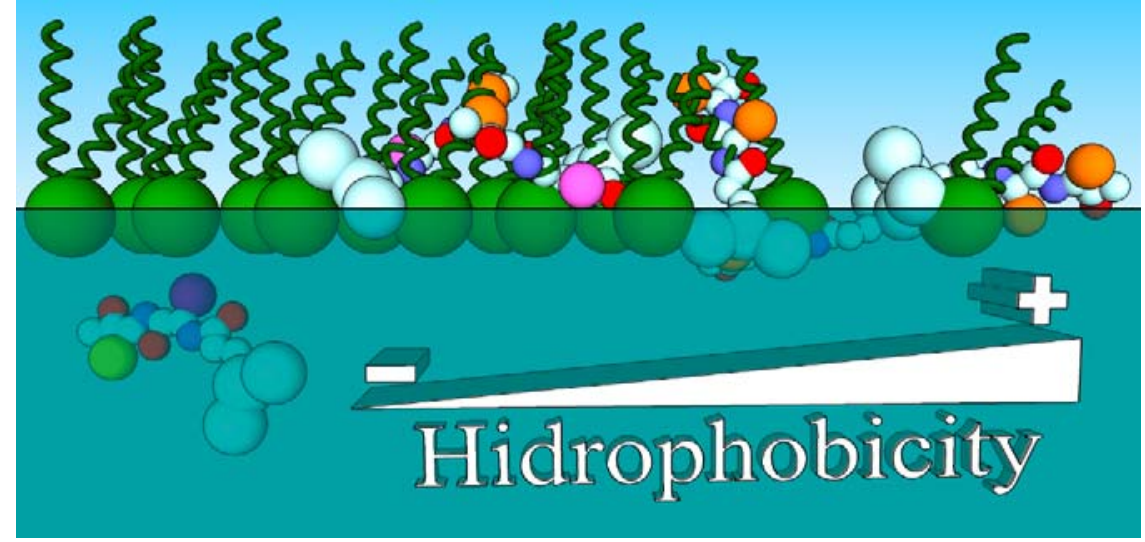

